\title{
An Idiopathic Thrombocytopenic Purpura Patient Treated With Homeopathy: A Case Report
}

\author{
Belinda Gousta ${ }^{1}$, Mohsen Saberi Isfeedvajani' ${ }^{2}$ * \\ ${ }^{1}$ Medicine, Quran and Hadith Research Center Baqiyatallah University of Medical Sciences, Tehran, IR Iran \\ ${ }^{2}$ Medicine, Quran and Hadith Research Center \& Department of Community Medicine, Faculty of Medicine, Baqiyatallah University of \\ Medical Sciences, Tehran, IR Iran
}

*Corresponding Author: Mohsen Saberi Isfeedvajani, Assistant Professor, Medicine, Quran and Hadith Research Center \& Department of Community Medicine, Faculty of Medicine, Baqiyatallah University of Medical Sciences, Shahid Nosrati Dead End, Sheik Bahaei Ave, Molla Sadra Ave, Tehran, Iran. Tel: +98-81263617, E-mail: drsaberihaji@gmail.com

Received: 1 Mar. 2016; Accepted: 9 Apr. 2016; Online Published: 28 May. 2016

\begin{abstract}
Introduction: Homeopathy can be applied to treat various diseases and conditions such as cancer, allergy, mood disorders, headache and pain. This case showed that homeopathic medicine can be a treatment modality for idiopathic thrombocytopenic purpura (ITP), an autoimmunemediated hematologic disorder.

Case Presentation: The patient was a 5.5-year-old child with ITP who referred to the homeopathic clinic with extensive petechiae and purpura on her body. Her platelet count was $15000 / \mathrm{mcL}$ and her anti-dsDNA and ANA were negative on her first visit. Her disease had first been diagnosed at the age of 2.5 years. She had undergone routine therapy for ITP; however, despite 15 months of corticosteroid therapy and IVIG injections, her platelet count was still low. After treatment with homeopathic remedies, her platelet count increased and signs of ITP disappeared.

Conclusion: Homeopathic remedies can be considered as complementary and alternative medicines for ITP treatment protocols.
\end{abstract}

Keywords: Homeopathy, Idiopathic Thrombocytopenic Purpura, Thrombopoietin Receptor, Hematologic Diseases

\section{Introduction}

Homeopathy, based on the ancient 'principle of similar,' is one of the most frequently used forms of complementary and alternative medicine (CAM). In homeopathy, highlydiluted preparations of substances that cause symptoms in healthy individuals are used to stimulate healing reactions in patients who display similar symptoms when ill [1]. Homeopathy is applied to treat various diseases and conditions such as cancer [2-7], allergies [8-16], mood disorders [17-19], cardiovascular diseases (CVD) [20, 21], osteoarthritis [22], hemophilia [23], headache [24, 25], and pain $[26,27]$.

Idiopathic thrombocytopenic purpura (ITP), one of the most common causes of symptomatic thrombocytopenia in children, is an autoimmune-mediated hematologic disorder in which the destruction of platelets occurs resulting in isolated thrombocytopenia, generally defined as a platelet count of less than $100000 / \mathrm{mcL}$, and normal results on a bone marrow examination (except possibly for increased megakaryocytes) [28-30]. About $60 \%$ of all pediatric cases have a prior history of infection, and most of them experience cutaneous bleeding. ITP is usually a selflimiting, childhood bleeding disorder, and spontaneous recovery is reported in about $50 \%$ to $70 \%$ of patients [28, 30]; however, some cases do require treatment. At present, most treatment protocols concentrate on reducing platelet destruction, and the drugs are usually immunosuppressive [28]. Various treatment modalities applied to treat ITP are corticosteroid therapy [29, 31, 32], IVIg injection [30, 31], splenectomy [29, 31-33], thrombopoietin receptor agonists (TPO-RAs) such as romiplostim, [29, 31, 32, 34], and rituximab [29, 32, 35].

Interestingly in this case, homeopathic medicines were used to treat idiopathic thrombocytopenic purpura after routine treatments of corticosteroid therapy and IVIg injection failed.

\section{Case Presentation}

The patient was a 5.5-year-old child from Jahrom in the Fars province of Iran who was referred to a homeopathic clinic for extensive petechiae and purpura on the abdomen, back, chest, upper and lower limbs, face, and eyes and sporadic ecchymosis on her upper and lower limbs. She had experienced high fever, vomiting, and petechiae on her back when she was 1 year and ten months old. The signs disappeared spontaneously without treatment, and viral infection was diagnosed. Two months later, she experienced more petechiae sporadically located on her body after fever. Coagulation tests produced normal results. Her parents reported that she experienced extensive bruising caused by very normal strikes when she was 2 years and 3 months old. Again when she was 2.5 years old, she experienced many petechiae and purpura on the abdomen, legs, back, eyes, and other sites after fever. Her complete blood count (CBC) showed a platelet count of $440000 / \mathrm{mcL}$. Idiopathic thrombocytopenic purpura (ITP) was suspected, and a bone marrow biopsy was performed on September 22, 2012. The results showed normal cellular marrow with increased megakaryocyte cells. Some days later, lab tests showed thrombocytopenia (platelet count = $104000 / \mathrm{mcL}$ ). Based on the bone marrow results and reduced platelet count, she was treated first with injectable and then with oral prednisolone for 6 months with dosages of $10 \mathrm{mg}, 10 \mathrm{mg}$, and $5 \mathrm{mg}$ at morning, evening, and night, respectively. Despite corticosteroid therapy, her platelet count decreased and extensive bruising and ecchymosis 
reappeared. The trend of platelet count decrease is shown in Table 1. Due to her very low platelet count (platelet count $=10000 / \mathrm{mcL}$ ), she was admitted to hospital on September 11, 2013 and received RhoGAM in addition to corticosteroid therapy. Her platelet count increased to $17000 / \mathrm{mcL}$ after injection. Two months later, she was admitted again for a very low platelet count (platelet count $=9000 / \mathrm{mcL}$ ) and received IVIG $0.5 \mathrm{gr}$ qd; her platelet count was $14000 / \mathrm{mcL}$ at discharge time. With the second IVIg injection, the patient experienced severe headache and vomiting and a brain CT scan was performed; results were normal. Despite 15 months pf corticosteroid therapy and IVIG injection, the patient's platelet count remained low. She referred to the homeopathic clinic on February 18, 2014. Extensive petechiae and purpura covering her abdomen, back, chest, upper and lower limbs, face, and eyes and sporadic ecchymosis on her upper and lower limbs were evident in the clinical examination. The patient's platelet count was $15000 / \mathrm{mcL}$ and anti-dsDNA and ANA were negative in laboratory tests performed on February 8 , 2014. The patient experienced diaphoresis on her head and neck area and thirst during sleep. Her feet were painful in cold weather and she was frequently affected with Common Cold. At her first visit, Sulph 6 c, Phos 6 c, Ham 30, and Arnica 30 were prescribed for the patient, and her parents were advised to continue Ars 30, Ham 30, and Cal 30 after termination of the mentioned drugs. The patient's parents tapered the prednisolone automatically after the first visit, and the hemato-oncologist stopped it on April 2014 because of clinical signs of improvement. At her second visit on June 14, 2014, most of the petechiae and purpura had disappeared; the patient had no nose bleeding, the diaphoresis on her head and neck area was decreased, and her overnight thirst had disappeared. Foot coldness and foot cold sensitivity was also decreased. Ars 30, Ham 30, and Cal 30 were re-prescribed. At her third visit on October 14, 2014 , her platelet count had risen to $36000 / \mathrm{mcL}$. Only sporadic petechiae was seen on her abdomen. Other body areas were intact and had no petechiae, purpura, or ecchymosis. A brief halo of the previous ecchymosis was detectable on her limbs. The patient experienced no nasal or gingival bleeding. Sulph 30, Phos 30, Bell 6, Ham 30, and Arnica 30 were prescribed on this visit. On the fourth visit in December 2014, the patient's platelet count had increased to $140000 / \mathrm{mcL}$ according to lab tests performed on December 28, 2014. All petechiae and purpura had disappeared. She experienced no new ecchymosis, bleeding, petechiae, or purpura. These results were obtained while she had received no chemical drugs and the prednisolone had been stopped 9 months earlier. During this 11-month period while the patient had only homeopathic drugs, her platelet count increased from $15000 / \mathrm{mcL}$ to $140000 / \mathrm{mcL}$ and all clinical signs disappeared. In the fourth visit, Sulp 30, Phos 30, and Ham 30 were prescribed. On her last visit on July 6, 2015, no clinical signs were detected. The patient's parents reported that bruising upon falling was within a normal range and disappeared after a few days. Sulp 30, Phos 30, Ham 30, and Arnica 30 were prescribed again. During the final two telephone contacts with the patient's parents in August and October 2015, they reported that the patient was completely healthy and had no dermal or mucosal signs.

\section{Discussion}

Pediatric ITP is considered to be self-limiting, and spontaneous recovery is reported in the majority of patients $[28,30]$; however, in this case, no spontaneous recovery was seen.

Table 1. Trend of platelet count over time

\begin{tabular}{ccc} 
& \multicolumn{2}{c}{ Table 1. Trend of platelet count over time } \\
\hline & Time of Lab Test & Plasma Count Per mcL \\
\hline 1 & August 22, 2012 & 440000 \\
2 & October 8, 2012 & 104000 \\
3 & October 29, 2012 & 89000 \\
4 & November 26, 2012 & 75000 \\
5 & December 29, 2012 & 131000 \\
6 & January 22, 2013 & 15000 \\
7 & January 26, 2013 & 133000 \\
8 & February 11, 2013 & 75000 \\
9 & May 2, 2013 & 20000 \\
10 & September 11, 2013 & 10000 \\
11 & September 18, 2013 & 17000 \\
12 & October 23, 2013 & 9000 \\
13 & October 30, 2013 & 14000 \\
14 & January 11, 2014 & 30000 \\
15 & February 8, 2014 & 15000 \\
16 & October 14, 2014 & 36000 \\
17 & December 28, 2014 & 140000 \\
\hline
\end{tabular}

Corticosteroid therapy is recommended as the first-line treatment [28], but the patient did not respond to prednisolone. As mentioned in some studies, a splenectomy may be recommended as another treatment [29, 31-33]; a splenectomy was not recommended as treatment in this case. Moreover, IVIg is prescribed for treatment as mentioned in some studies [30, 31]; this patient did not respond to it. Other studies have recommended the use of thrombopoietin receptor agonists (TPO-RAs) such as romiplostim [29, 31, 32, 34], but rituximab [29, 32, 35] was not recommended for her as the third line of ITP treatment.

It has been reported that homeopathy as a CAM can be applied to treat various diseases and conditions [2-7], however, no study has reported the use of homeopathy in treating ITP. Only one study has reported the role of homeopathic medicines in a patient with hemophilia (23).

\section{Conclusion}

Homeopathic remedies can be considered as complementary and alternative medicines for ITP treatment protocols because of their mechanisms of action. As noted, homeopathic remedies can be suggested as cost-effective secondary or tertiary treatment modalities.

\section{Acknowledgments}

The authors would like to express their deepest gratitude to the "Clinical Research Development Unit" of the Baqiyatallah Hospital for their kind cooperation.

\section{Authors' Contributions}

$\mathrm{BG}$ visited and followed-up with the patient. BG recorded patient data and prepared the case presentation. MSI reviewed the literature and prepared the introduction, discussion, and conclusion sections of this paper. BG and MSI performed the final review of this manuscript and approved it for publication.

\section{Conflict of Interest}

None declared.

\section{References}

1. Teut M, Lüdtke R, Schnabel K, Willich SN, Witt CM. Homeopathic treatment of elderly patients-a prospective observational study with follow-up over a two year period. BMC Geriatr. 2010;10(1):10. [DOI] 
2. Rostock M, Naumann J, Guethlin C, Guenther L, Bartsch HH, Walach H. Classical homeopathy in the treatment of cancer patients-a prospective observational study of two independent cohorts. BMC Cancer. 2011;11(1):19. [DOI]

3. Längler A, Spix C, Edelhäuser F, Kameda G, Kaatsch P, Seifert G. Use of homeopathy in pediatric oncology in Germany. Evid Based Complement Alternat Med. 2010;2011.

4. de Carvalho AC, Bonamin LV. Viscum album (L) extracts in cancer treatment: a systematic review of in vitro and in vivo studies. Int J High Dilut Res. 2015;14(2).

5. Tenti E, Gardini AC, Nanni O, Foca F, Cumero S. Use of nonconventional medicines by cancer patients. Eur J Oncol. 2015;19(3):144-9.

6. Bishayee K, Mondal J, Sikdar S, Khuda-Bukhsh AR. Condurango (Gonolobus condurango) Extract Activates Fas Receptor and Depolarizes Mitochondrial Membrane Potential to Induce ROS dependent Apoptosis in Cancer Cells in vitro: CE-treatment on HeLa: a ROS-dependent mechanism. J Pharmacopuncture. 2015;18(3):32-41. [DOI]

7. Sikdar S, Kumar Saha S, Rahman Khuda-Bukhsh A. Relative Apoptosis-inducing Potential of Homeopa-thic Condurango 6C and 30C in H460 Lung Cancer Cells In vitro: -Apoptosis-induction by homeopathic Condurango in $\mathrm{H} 460$ cells. J Pharmacopuncture. 2014;17(1):59-69. [DOI]

8. Banerjee K, Costelloe C, Mathie RT, Howick J. Homeopathy for allergic rhinitis: protocol for a systematic review. Syst Rev. 2014;3(1):59. [DOI]

9. Solelhac G, Charpin D. Management of allergic rhinitis. F1000Prime Rep. 2014;6:94. [DOI]

10. Roll S, Reinhold T, Pach D, Brinkhaus B, Icke K, Staab D, et al Comparative effectiveness of homoeopathic vs. conventional therapy in usual care of atopic eczema in children: long-term medical and economic outcomes. PLoS One. 2013;8(1):e54973. [DOI]

11. Naidoo P, Pellow J. A randomized placebo-controlled pilot study of Cat saliva $9 \mathrm{cH}$ and Histaminum $9 \mathrm{cH}$ in cat allergic adults. Homeopathy. 2013;102(2):123-9. [DOI]

12. Eizayaga JE, Eizayaga JI. Prospective observational study of 42 patients with atopic dermatitis treated with homeopathic medicines. Homeopathy. 2012;101(1):21-7. [DOI]

13. Shafei HF, AbdelDayem SM, Mohamed NH. Individualized homeopathy in a group of Egyptian asthmatic children. Homeopathy. 2012;101(4):224-30. [DOI]

14. Chandrakant Nimgulkar C, Dattatray Patil S, Dinesh Kumar B. Anti-asthmatic and anti-anaphylactic activities of Blatta orientalis mother tincture. Homeopathy. 2011;100(3):138-43. [DOI]

15. Grundling C, Schimetta W, Frass M. Real-life effect of classical homeopathy in the treatment of allergies: A multicenter prospective observational study. Wien Klin Wochenschr. 2012;124(1-2):11-7. [DOI]

16. Rossi E, Bartoli P, Bianchi A, Da Fre M. Homeopathy in paediatric atopic diseases: long-term results in children with atopic dermatitis. Homeopathy. 2012;101(1):13-20. [DOI]

17. Qureshi NA, Al-Bedah AM. Mood disorders and complementary and alternative medicine: a literature review. Neuropsychiatr Dis Treat. 2013;9:639-58. [DOI]

18. Adler UC, Krüger S, Teut M, Lüdtke R, Schützler L, Martins F, et al. Homeopathy for depression: A randomized, partially doubleblind, placebo-controlled, four-armed study (DEP-HOM). PLoS One. 2013;8(9):e75537. [DOI]

19. del Carmen Macías-Cortés E, Llanes-González L, Aguilar-Faisal L Asbun-Bojalil J. Individualized Homeopathic Treatment and Fluoxetine for Moderate to Severe Depression in Peri-and
Postmenopausal Women (HOMDEP-MENOP Study): A Randomized, Double-Dummy, Double-Blind, Placebo-Controlled Trial. PLoS One. 2015;10(3):e0118440. [DOI]

20. Schröder D, Weiser M, Klein P. Efficacy of a homeopathic Crataegus preparation compared with usual therapy for mild (NYHA II) cardiac insufficiency: results of an observational cohort study. Eur J Heart Fail. 2003;5(3):319-26. [DOI]

21. Mehra P. Usefulness of homoeopathy in essential hypertension: an exploratory interventional trial. Int J High Dilut Res. 2015;14(1):169.

22. Koley M, Saha S, Ghosh S. A double-blind randomized placebocontrolled feasibility study evaluating individualized homeopathy in managing pain of knee osteoarthritis. J Evid Based Complementary Altern Med. 2015;20(3):186-91. [DOI]

23. Kundu T, Shaikh A, Kutty A, Nalvade A, Kulkarni S, Kulkarni R, et al. Homeopathic medicines substantially reduce the need for clotting factor concentrates in haemophilia patients: results of a blinded placebo controlled cross over trial. Homeopathy. 2012;101(1):38-43. [DOI]

24. Posadzki P, AlBedah A, Khalil MM, AlQaed MS, Lee MS, Ernst E, et al. Complementary and alternative medicine for the prevention and treatment of migraine headache: an overview of systematic reviews. Focus Altern Complement Ther. 2015;20(2):58-73. [DOI]

25. Danno K, Colas A, Masson JL, Bordet MF. Homeopathic treatment of migraine in children: results of a prospective, multicenter, observational study. J Altern Complement Med. 2013;19(2):119-23. [DOI]

26. Simpson CA. Complementary Medicine in Chronic Pain Treatment Phys Med Rehabil Clin N Am. 2015;26(2):321-47. [DOI]

27. Kelley BP, Shauver MJ, Chung KC. Management of Acute Postoperative Pain in Hand Surgery: A Systematic Review. J Hand Surg. 2015;40(8):1610-9. e1.

28. Alam MM. Idiopathic thrombocytopenic purpura in children: a 10 years experience at tertiary care hospital. J Pak Med Assoc. 2014;64(12):1358-62.

29. Kikuchi K, Miyakawa Y, Ikeda S, Sato Y, Takebayashi T. Costeffectiveness of adding rituximab to splenectomy and romiplostim for treating steroid-resistant idiopathic thrombocytopenic purpura in adults. BMC Health Serv Res. 2015;15(1):2. [DOI]

30. Dash CH, Gillanders KR, Stratford Bobbitt ME, Gascoigne EW, Leach SJ. Safety and efficacy of Gammaplex(R) in idiopathic thrombocytopenic purpura (ClinicalTrials.gov--NCT00504075). PLoS One. 2014;9(6):e96600. [DOI]

31. Ramakrishna R, Rehman A, Ramakrishna S, Alexander W, Yeo W. Use of Romiplostim in Patients with Chronic Idiopathic Thrombocytopenic Purpura (cITP) During Peri-Operative Period. Internal Med J. 2015.

32. Zhou H, Xu M, Qin P, Zhang H-y, Yuan C-1, Zhao H-g, et al. A multicenter randomized open-label study of rituximab plus rhTPO vs rituximab in corticosteroid-resistant or relapsed ITP. Blood. 2015;125(10):1541-7. [DOI]

33. Vecchio R, Intagliata E, La Corte F, Marchese S, Cacciola RR, Cacciola E. Late Results After Splenectomy in Adult Idiopathic Thrombocytopenic Purpura. JSLS. 2015;19(1).

34. Walsh AV, Collados NJ, Andújar MC, Gomez CG, Candel GR, Paniagua SP, et al. DI-077 Use of romiplostim in patients with idiopathic thrombocytopenic purpura. Eur J Hospl Pharm. 2015;22(Suppl 1):A108-A9.

35. Clark WF, Rock G, Barth D, Arnold DM, Webert KE, Yenson PR, et al. A phase-II sequential case-series study of all patients presenting to four plasma exchange centres with presumed relapsed/refractory thrombotic thrombocytopenic purpura treated with rituximab. $\mathrm{Br} \mathrm{J}$ Haematol. 2015;170(2):208-17. [DOI] 